\title{
The use of distilled water in the achievement of local hemostasis during surgery
}

\author{
S. A. H. M. van den Tillaart • M. P. H. Busard • \\ J. B. M. Z. Trimbos
}

Received: 18 November 2008 / Accepted: 29 December 2008 / Published online: 17 January 2009

(C) The Author(s) 2009. This article is published with open access at Springerlink.com

\begin{abstract}
Distilled water is used worldwide to check on hemostasis at the end of pelvic oncological operations. Nevertheless, reports about this method are lacking. The aim of this study was to explain the method and to discuss possible side effects. After the addition of distilled water to the surgically exposed pelvis, rapid lysis of erythrocytes results in a transparent fluid in which a small source of bleeding is easily recognizable. A possible side effect of the lavage might be contribution to the formation of peritoneal adhesions by confusing the abdominal defence system. Systemic side effects are not to be expected. Although tumour cells might suffer from hypotonic distilled water lavage, the current use of distilled water at the end of surgery is probably not effective to lyse tumour cells. Our findings support the ongoing use of distilled water lavage to achieve hemostasis after extensive pelvic surgery.
\end{abstract}

Keywords Lavage · Hemostasis · Distilled water Water . Aquadest $\cdot$ Gynaecologic oncologic surgery

The corresponding author certifies that there is no actual or potential conflict of interest in relation to this article.

S.A.H.M. van den Tillaart and M.P.H. Busard contributed equally to this work.

S. A. H. M. van den Tillaart $(\bowtie) \cdot$ M. P. H. Busard •

J. B. M. Z. Trimbos

Department of Gynaecology K6-P,

Leiden University Medical Center,

P.O. Box 9600, 2300 RC Leiden, The Netherlands

e-mail: s.a.h.m.van_den_tillaart@lumc.nl

\section{Introduction}

After extensive pelvic surgery, e.g. oncological operations or surgery for endometriosis, the surgeon can be confronted with a raw, oozing area in the pelvis. Stopping small venous bleeders to achieve adequate hemostasis is often a difficult task in these areas. Distilled water lavage makes the detection of the sources of bleeding much easier. While lavage with $\mathrm{NaCl} 0.9 \%$ to clean the operation field after surgery is widely accepted and often mentioned in literature, strangely enough we haven't seen any publication on the use of distilled water (aquadest). The aim of this report is to explain the use of distilled water for the purpose of achieving hemostasis during surgery. Besides informing about its usefulness and ease, we want to provide background information about the mechanism that makes distilled water applicable for this purpose. Apart from the beneficial effects of distilled water, it is imaginable that the addition of a hypotonic fluid as such to the pelvis might not be without any side effects. We briefly discuss these elements.

\section{Mechanism}

\section{Clinical application}

Before closing the abdomen, $500 \mathrm{cc}$ of distilled water is poured into the abdominal cavity. In contrast to $\mathrm{NaCl} 0.9 \%$, which gives a blurred view through an opaque fluid, distilled water remains clearly transparent and ensures a bright sight in the small pelvis. As a consequence, small venous bleeding is easily recognizable and the bleeding site can be accurately traced. When sources of bleeding have 
thus been discovered, the distilled water is suctioned out of the pelvis and the bleedings are stopped in the appropriate way. In general, two sequential lavages are used. Figure 1 shows two examples.

\section{Physiology}

Within a certain range of external solute concentrations, erythrocytes behave as an osmometer: their volume is inversely related to the solute concentration in a medium. The erythrocyte shrinks in hypertonic solutions and swells in hypotonic solutions. When an erythrocyte has swollen to about 1.4 times its original volume, it begins to lyse (burst). At this volume the properties of the cell membrane abruptly change, haemoglobin leaks out of the cell and the membrane becomes transiently permeable to most molecules [1].

$\mathrm{NaCl}$ is isotonic to the red blood cell at a concentration of $154 \mathrm{mM}$. This corresponds with $\mathrm{NaCl} 0.9 \%$. The red blood cell has its normal volume in isotonic $\mathrm{NaCl}$. Erythrocytes remain intact in $\mathrm{NaCl} 0.9 \%$, resulting in an opaque suspension. Distilled water on the other hand is hypotonic to red blood cells. The red blood cell will

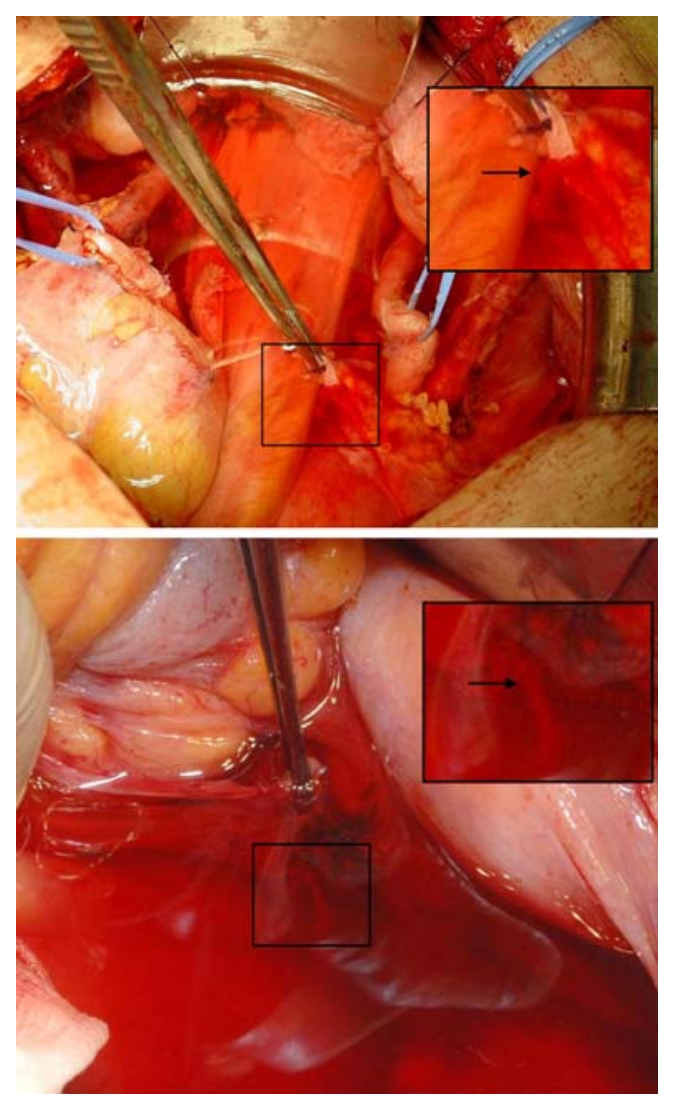

Fig. 1 Two examples of the use of distilled water to localize small venous bleeding sites. The water is clearly transparent. The arrows point to the emerging stream of blood therefore swell and haemoglobin, containing the haem that gives the red colour to erythrocytes, leaks from the cell resulting in a transparent red-pink-coloured solution. Apparently, erythrocytes in clear fluid colour the fluid red and opaque, whereas haemoglobin in clear fluid leaves the fluid transparent.

\section{Laboratory experiment}

To further explore the appearance of a traceable blood stream when using distilled water lavage, we performed an in vitro experiment. Ten microlitres of human erythrocytes was injected in tubes containing $990 \mu \mathrm{l} \mathrm{NaCl} 0.9 \%$ or distilled water (concentration 1:100). A traceable stream dropping to the bottom was visible in both tubes. After stirring the tubes both solutions got turbid, but for the distilled water solution this only lasted a moment. Approximately $5 \mathrm{~s}$ after the stirring, the distilled water solution turned bright red-pink, clearly transparent. The $\mathrm{NaCl}$ solution stayed opaque red-pink. After $30 \mathrm{~s}$, a drop of fluid of both solutions was examined under the microscope. In the $\mathrm{NaCl}$ solution, normal erythrocytes were visible, whereas no normal erythrocytes were visible in the distilled water solution. Subsequently, another $10 \mu 1$ of erythrocytes was added to both solutions. The traceable stream was visible again in the red-pink distilled water solution, whereas a stream could not be seen in the turbine $\mathrm{NaCl}$ solution. Some time after stirring, the distilled water solution turned bright red-pink again, while the $\mathrm{NaCl}$ solution got more opaque. Successively, volumes of $10 \mu \mathrm{l}$ erythrocytes were added to the tubes. When continuing the process, it took longer before the distilled water solution turned bright red-pink after stirring and the colour of the solution got darker. At a concentration of 16:115 $\left(160 \mu \mathrm{l}\right.$ erythrocytes in $\left.990 \mu \mathrm{l} \mathrm{H}_{2} \mathrm{O}\right)$, the distilled water solution was no longer transparent and a blood stream was not visible anymore.

This experiment mimics the clinical situation and shows that a traceable blood stream does appear in both distilled water and $\mathrm{NaCl} 0.9 \%$, but is only visible in a transparent fluid. In contrast to $\mathrm{NaCl}$, distilled water retains its transparency after the addition of blood as a result of the rapid lysis of erythrocytes. The difference in transparency can be compared with the difference between fruit juice $(\mathrm{NaCl})$ and lemonade (distilled water). Erythrocytes added to the solution cause the osmolarity of the solution to rise, and the difference in hydrostatic pressure to decrease, resulting in a prolonged time of cell lysis. Probably because more intact or swollen erythrocytes will be present in the distilled water solution after continuous mixing with blood or other intra-abdominal fluid, the solution becomes less transparent. This sometimes necessitates more than one lavage cycle. 


\section{Possible side effects}

\section{Peritoneal damage}

Peritoneal mesothelial cells play a primary role in the abdominal defence system. They can express specific surface markers that enable them to promote the margination and migration of neutrophil granulocytes and produce important molecules such as pro-inflammatory cytokines, nitric oxide, growth molecules, tissue plasminogen activator and plasminogen activator inhibitor [2]. Peritoneal mast cells have been shown to have a direct effect on peritoneal adhesion formation. Mast cell mediators induce fibroblast proliferation and mast cell hyperplasia has been shown to be present in human peritoneal adhesions [3].

It is not known by which mechanism peritoneal mesothelial cells behave when exposed to different concentrations of lavage solutions, but they are damaged by solutions that are far from physiological, such as peritoneal dialysis fluids. Even solutions that are more physiological have been shown to cause changes in synthesis of specific molecules [4-6]. In vitro studies showed that peritoneal lavage with normal saline causes up-regulation of proinflammatory cytokines, and that per-operative lavage solutions influence the peritoneal defence mechanisms. Both antiseptic lavage solutions and physiologic salt caused cell death and decreased integrity in the mesothelial monolayer $[7,8]$.

Polubinska et al. performed an in vitro study of mesothelial monolayers exposed to $\mathrm{NaCl} 0.9 \%$ and different peritoneal dialysis fluids, including hypertonic solutions with low glucose degradation products concentration. Although the hypertonic fluid caused damage to the cell membrane, the viability of the cells was not reduced and fybrinolytic activity was preserved. In contrast, cells exposed to $\mathrm{NaCl} 0.9 \%$ showed changes that could promote the formation of peritoneal adhesion formation. In a rat study of this group, hypertonic lavage solution was reported to suppress intra-peritoneal inflammation and mesothelial hyperplasia as compared to normal saline. The authors advise the use of hypertonic solutions with low glucose degradation products concentration for both peritoneal dialysis and rinsing of the peritoneal cavity per-operatively $[6,9]$. However, hypotonic solutions were not studied and the effects reported in this study could probably be attributed to the glucose dehydration product concentration rather than to osmolarity itself. Adhesion formation was not studied and the study groups were small. Kanakura et al. studied numbers and types of mast cells in the peritoneal cavity of mice after injection of distilled water or saline. Although the intra-peritoneal injection of saline did not significantly affect the number of peritoneal mast cells, the intra-peritoneal injection of distilled water eradicated small and medium (differentiated) mast cell colony-forming cells, while the number of large mast cell colonies increased [10].

The effects of lavage fluid volume and incubation time on the above-described mechanisms are not known, neither is their role in vivo.

Based on the existing literature, we assume that peritoneal lavage with any solution will result in disturbance of the homeostasis in the pelvis. Lavage with distilled water might alter the abdominal defence system by up-regulation of proinflammatory mediators. This might lead to the formation of adhesions. The extent of this effect of distilled water in proportion to other media is not clear. The same mechanisms might damage the lining of the per-operatively exposed organs and tissues, but we have no means to accurately quantify this effect in vivo.

\section{Systemic effects}

One can speculate on a systemic effect of distilled water pelvic lavage. The absorption of distilled water used as an irrigation fluid in endoscopic procedures has been reported to disturb the circulatory system and lead to clinical symptoms known as the transurethral resection (TURP) syndrome. Acute changes in intravascular volume and plasma solute concentrations might contribute to hypotension, and even acute renal failure has been reported [11]. Hypotonic distilled water directly entering the circulation through opened veins or absorbed more slowly, can cause haemolysis. Intra-vesicular pressure above $30 \mathrm{mmHg}$ and increasing resection time have been proposed to increase the absorption of fluid [12, 13]. Averagely, 151 of irrigation fluid is used during a 60-minlasting TURP procedure $[14,15]$. Still, severe changes in blood values after TURP with distilled water were rarely reported and it has been shown to be a safe irrigating fluid for TURP [15].

Since in the procedure we describe only small volumes of distilled water are used for a short time at the end of the surgical procedure and without pressure, we have no reason to suspect systemic side effects as a result of the application of distilled water in the pelvis at the end of the surgical procedure.

\section{Lysis of tumour cells}

Besides possible negative side effects, distilled water lavage to attain hemostasis might also have an unintentional beneficial effect.

Although there is no consensus about the optimal lavage method, e.g. incubation time to achieve effective lysis and the potential of sequential lavages, several studies showed a harmful effect of distilled water on tumour cells. Human tumour cell lines seem to be sensitive to osmotic shock in vitro. Fechner et al. found significant bladder tumour cell 
dead after 10 min of exposure to distilled water lavage [16]. Mercill et al. observed a decrease in DNA synthesis in different tumour cell lines after exposure to distilled water for 1 to $10 \mathrm{~min}$. However, the remaining cells did not lose their replication capacity [17]. In a study of Huguet et al., colorectal cancer cell lines were incubated with distilled water and no surviving cells were found beyond $12 \mathrm{~min}$ incubation. Water introduced into the peritoneal cavity in vivo was contaminated by intra-peritoneal secretions, compromising the osmotic lysis effect. However, this contamination was reduced by sequential lavages: after three lavages a final resultant osmolarity of $10 \mathrm{mM}$ was attained. A solution of $10 \mathrm{mM}$ was able to produce $100 \%$ cell lysis of colorectal cancer cells in vitro after $32 \mathrm{~min}$ of incubation [18]. Lin et al. found that the application of 101 of distilled water divided into at least five cycles retained for 3 min resulted in a significant better survival time after curative liver resection in patients with spontaneous rupture of hepatocellular carcinoma [19]. Although it is assumed that tumour cell injury is caused by osmotic shock, the exact mechanism of potential cell injury by distilled water is not known. Selzner et al. assessed the effects of 1, 3 and $5 \mathrm{~min}$ of hypotonic exposure on cell viability in three different human colon cancer cell lines. All three cell lines challenged with distilled water exhibited a dramatic decrease in viability in a time-dependent manner, but only exposure of $>15 \mathrm{~min}$ to distilled water was associated with significant increases in cell lysis. According to Selzner N et al. cell death is related to temporary cell swelling that triggers activation of apoptosis. Essential receptors for this apoptosis pathway were not detected in normal cells (human fibroblasts) after a challenge with either distilled water or isotonic media [20].

Based on these reports we assume that the lavage method that we use to achieve hemostasis is not adequate for complete tumour cell lysis. The incubation time is short and numbers of lavages are relatively small. Nevertheless, free tumour cells in the pelvis might to some extent suffer from hypotonic distilled water lavage.

\section{Conclusion}

Distilled water is a helpful tool to achieve hemostasis peroperatively. Erythrocytes burst in the hypotonic distilled water, ensuring a transparent solution in which a blood stream can be easily traced to its origin. After suctioning the water out of the pelvis, bleedings can be stopped.

The impact of the method on the total amount of blood loss or operating time can not easily be estimated since other per-operative factors outweigh the effect of distilled water in that respect, but distilled water is certainly relevant for surgeons during a difficult step of the surgical procedure.
A possible negative side effect of this method is damage to the peritoneal mesothelial cells. Distilled water lavage might confuse the abdominal defence system and might contribute in this way to the formation of peritoneal adhesions. We could not assess the possible harmful effect of distilled water lavage on surgically exposed surfaces. The described method is not suspected to cause systemic side effects during or shortly after surgical treatment. Distilled water lavage might induce tumour cells lysis, but the currently used method is probably not sufficient to achieve this beneficial effect.

In the absence of evident indications on possible negative side effects of distilled water lavage as described above, we consider it sufficiently safe to apply this useful method in surgical practice.

Open Access This article is distributed under the terms of the Creative Commons Attribution Noncommercial License which permits any noncommercial use, distribution, and reproduction in any medium, provided the original author(s) and source are credited.

\section{References}

1. Berne RM, Levy MN, Stanton BA (1998) Physiology. 4 ed. Mosby

2. Hall JC, Heel KA, Papadimitriou JM, Platell C (1998) The pathobiology of peritonitis. Gastroenterology 114:185-196

3. Xu X, Rivkind A, Pappo O, Pikarsky A, Levi-Schaffer F (2002) Role of mast cells and myofibroblasts in human peritoneal adhesion formation. Ann Surg 236:593-601

4. Dobbie JW (1992) Pathogenesis of peritoneal fibrosing syndromes (sclerosing peritonitis) in peritoneal dialysis. Perit Dial Int $12: 14-27$

5. Boulanger E, Wautier MP, Gane P, Mariette C, Devuyst O, Wautier JL (2004) The triggering of human peritoneal mesothelial cell apoptosis and oncosis by glucose and glycoxydation products. Nephrol Dial Transplant 19:2208-2216

6. Polubinska A, Winckiewicz M, Staniszewski R, Breborowicz A, Oreopoulos DG (2006) Time to reconsider saline as the ideal rinsing solution during abdominal surgery. Am J Surg 192:281285

7. Yao V, Platell C, Hall JC (2005) Lavage enhances the production of proinflammatory mediators by peritoneal mesothelial cells in an experimental model. Dis Colon Rectum 48:560-566

8. van WM, Mul FJ, Pronk A et al (1999) Influence of peroperative lavage solutions on peritoneal defence mechanisms in vitro. Eur J Surg 165:1066-1071

9. Styszynski A, Podkowka R, Wieczorowska-Tobis K et al (2002) Glucose suppresses peritoneal inflammatory reactions and mesothelial hyperplasia caused by intraperitoneal saline infusion. Adv Perit Dial 18:21-25

10. Kanakura Y, Kuriu A, Waki N et al (1988) Changes in numbers and types of mast cell colony-forming cells in the peritoneal cavity of mice after injection of distilled water: evidence that mast cells suppress differentiation of bone marrow-derived precursors. Blood 71:573-580 
11. Gravenstein D (1997) Transurethral resection of the prostate (TURP) syndrome: a review of the pathophysiology and management. Anesth Analg 84:438-446

12. Hjertberg H, Pettersson B (1992) The use of a bladder pressure warning device during transurethral prostatic resection decreases absorption of irrigation fluid. Br J Urol 69:56-60

13. Chen SS, Lin AT, Chen KK, Chang LS (2006) Haemolysis in transurethral resection of the prostate using distilled water as the irrigant. J Chin Med Assoc 69:270-275

14. Hjertberg H, Jorfeldt L, Schelin S (1991) Use of ethanol as marker substance to increase patient safety during transurethral prostatic resection. Screening investigation of irrigating fluid absorption in four hospitals and comparison of experienced and inexperienced urologists. Urology 38:423-428

15. Moharari RS, Khajavi MR, Khademhosseini P, Hosseini SR, Najafi A (2008) Sterile water as an irrigating fluid for transurethral resection of the prostate: anesthetical view of the records of 1600 cases. South Med J 101:373-375
16. Fechner G, Pocha K, Schmidt D, Muller SC (2006) Reducing recurrence and costs in superficial bladder cancer: preclinical evaluation of osmotic cytolysis by distilled water vs. mitomycin. Int J Clin Pract 60:1178-1180

17. Mercill DB, Jones NR, Harbell JW (1985) Human tumour cell destruction by distilled water. An in vitro evaluation. Cancer 55:2779-2782

18. Huguet EL, Keeling NJ (2004) Distilled water peritoneal lavage after colorectal cancer surgery. Dis Colon Rectum 47:2114 2119

19. Lin CH, Hsieh HF, Yu JC, Chen TW, Yu CY, Hsieh CB (2006) Peritoneal lavage with distilled water during liver resection in patients with spontaneously ruptured hepatocellular carcinomas. J Surg Oncol 94:255-256

20. Selzner N, Selzner M, Graf R, Ungethuem U, Fitz JG, Clavien PA (2004) Water induces autocrine stimulation of tumour cell killing through ATP release and P2 receptor binding. Cell Death Differ 11 (Suppl 2):S172-S180 